\title{
LOS DESEQUILIBRIOS PROCESALES EN LA RESTITUCIÓN DE TIERRAS BAJO EL MODELO COLOMBIANO DE JUSTICIA TRANSICIONAL
}

\author{
Rosa Angélica Vergara Mendoza ${ }^{1}$ \\ Ángel Andrés Torres Hernández ${ }^{2}$ \\ Daniela Alejandra González López ${ }^{3}$
}

\begin{abstract}
Resumen
El objetivo de nuestro trabajo consiste en establecer los efectos negativos que ha generado el proceso de restitución de tierras bajo el modelo de justicia transicional en la sociedad colombiana, con la exigencia de la demostración de la buena fe exenta de culpa a cargo del demandado, pudiendo resultar contrario a los principios de este sistema de justicia que propenden de manera general a obtener la verdad, justicia, reparación y la garantía de no repetición.

Por tratarse de una investigación teórica, se realizó un análisis documental de fuentes legales relativas al tema, de la doctrina nacional y extranjera y jurisprudencia de las altas cortes, especialmente de la Corte Constitucional. Como resultado del mismo, se encontró que los procesos judiciales de restitución de tierras, de manera general, por la aplicación de la exigencia procesal de la buena fe exenta de culpa ha generado, en muchos casos, situaciones de inconformidad, inclusive conductas violentas entre las partes en contienda, siendo entonces un obstáculo para lograr la reconciliación nacional y la paz duradera y sostenible que se pregona.
\end{abstract}

Palabras Clave: Justicia transicional, buena fe, carga de la prueba, restitución de tierras, víctima, opositor.

1 Estudiante de VIII semestre de Derecho y miembro del Semillero de derecho procesal de Corposucre. Email: rosa_vergara@corposucre.edu.co

2 Magíster en Derecho. Especialista en Derecho Tributario y en Gerencia de la Hacienda Pública Abogado y Contador Público. Email: angel_torres@corposucre.edu.co

Docente investigador de Corposucre y director del Semillero de derecho procesa

${ }^{3}$ Estudiante de VIII semestre de Derecho y miembro del Semillero de derecho procesal de Corposucre. Email: daniela_gonzalez@corposucre.edu.co 
Rosa A. Vergara. Ángel A. Torres. Daniela A. González

\begin{abstract}
The objective of our work was to establish the effects of imbalances incorporated to the process of restitution of lands under the model of transitional justice in Colombian society, taking into account that the principles of this normative system generally aims, truth, justice, Repair and the guarantee of non-repetition.

Based on the fact that it is a theoretical investigation, a documentary analysis of sources such as legal norms concerning the subject, jurisprudence, national doctrine and comparative law was carried out. As a result, the implementation of the rule has generated more violence on leaders and claimants of land restitution, without being able to envisage national reconciliation and lasting and sustainable peace.
\end{abstract}

Keywords: Transitional justice, good faith, burden of proof, land restitution, victim, opponent.

\title{
Introducción
}

耳

studiaremos el marco normativo de la justicia transicional aplicada al proceso de restitución de tierras, revisando inicialmente los principios de este sistema jurídico y su aplicación como herramienta para la búsqueda de la paz, en la solución de conflictos armados y violaciones de derechos humanos. Miraremos algunos casos puntuales de experiencias de países donde se ha aplicado este sistema, para luego precisar los antecedentes históricos de la justicia transicional en el orden nacional, como herramientas para la búsqueda de la paz (Carnelutti, 1997).

Por otra parte, revisaremos la Ley de Victimas y Restitución de tierras, además de jurisprudencias, relacionadas con el proceso de restitución de tierras ideado como parte de reparación a las víctimas del conflicto armado, con el fin de determinar sí se conceden ciertos privilegios procesales en favor de los demandantes/reclamantes y en contra de los demandados/opositores/poseedores, lo cual soportaría nuestra hipótesis de trabajo que es la existencia de exigencias procesales que desequilibran el proceso en favor del reclamante, específicamente con la carga de la prueba de la demostración de la buena fe exenta de culpa para los opositores/demandados, cuya aplicación no ha sido homogénea por parte de los operadores judiciales encargados de dirimir esas controversias. Pudiéndose con ello 
no lograr el objetivo buscado por la ley, sino ser una nueva fuente de controversias generadoras de conflictos entre los poseedores de buena fe que terminan siendo expulsados de los predios ocupados por ellos, los reclamantes y el Estado.

En este orden de ideas, corresponde resolver al Semillero de Derecho Procesal la siguiente pregunta ¿La exigencia procesal de la buena fe exenta de culpa a cargo del demandado, desequilibra el proceso de restitución de tierras a favor del demandante/reclamante, poniendo en riesgo la reconciliación y la paz duradera?

\section{La justicia transicional y su fuente material}

Siempre se ha sostenido que la fuente material es la verdadera fuente del derecho y originan que el legislador produzca las fuentes formales o las normas escritas, estas se conocen como "los factores y elementos que determinan el contenido de tales normas. Estos factores son las necesidades o problemas (culturales, económicos, gremiales, etc.) que el legislador tiende a resolver, y, además, las finalidades o valores que el legislador quiere realizar en el medio social para el que legisla" (Torré, 2010, p.156). En este caso, tal fuente está constituida por la violencia social y los conflictos armados ya sea entre naciones o internos.

En los países de conflicto armado, es evidente la permanente violación de derechos humanos por parte los actores del conflicto, por consiguiente, se hace necesario un ordenamiento jurídico especial que equilibre la balanza de la diosa Temis en favor de los coasociados más vulnerados o víctimas. Ese ordenamiento normativo particular, se conoce como justicia transicional, que de acuerdo con el ICTJ es una respuesta a las violaciones sistemáticas o generalizadas a los derechos humanos. Su objetivo es reconocer a las víctimas y promover iniciativas de paz, reconciliación y democracia. La justicia transicional no es una forma especial de justicia, sino una justicia adaptada a sociedades que se transforman a sí mismas después de un período de violación generalizada de los derechos humanos (Centro internacional para la justicia transicional, 2009). 
Por otra parte, de acuerdo con el libro Aprendizaje Significativo de la Ley de Justicia y Paz, apoyado por la Embajada de la República Federal Alemana en Bogotá, manifiesta que

La Justicia transicional es una modalidad jurídica que busca colaborar en la conversión de un Estado de violencia y de ausencia de garantías democráticas, a un Estado de paz y respeto por las libertades civiles; excepcional, contingente y especifica; un mecanismo tendiente al logro de la justicia, la verdad, la reparación y la garantía de no repetición, y un elemento insoslayable para la consolidación de la paz de la paz. (Bernal \& Alvarez, 2009)

Bajo esta modalidad, como lo que se pretende es un fin invaluable como la paz, el Estado deberá adelantar procesos de transición tendientes a aliviar los derechos vulnerados de las víctimas de violaciones graves de derechos humanos.

Para ello se adopta la tipificación empleada por Louis Joinet en el Informe Final del Relator Especial sobre la impunidad y Conjunto de principios para la protección y la promoción de los derechos humanos mediante la lucha contra la impunidad (Joinet, 1997), según el cual, los Estados tienen cuatro obligacio- nes inderogables, exigibles incluso en procesos de transición: (1) la satisfacción del derecho a la justicia, (2) la satisfacción del derecho a la verdad, (3) la satisfacción del derecho a la reparación de las víctimas, y (4) la adopción de reformas institucionales y otras garantías de no repetición. (Uprimny, 2006)

Todos los principios anteriormente planteados son igualmente relevantes, empero, si lo que se trata es de resolver un conflicto hacia futuro, lo pri- mero que debemos enfocar es, que los procesos que se enmarquen en esta justicia, garanticen la no repetición de los hechos violatorios de derechos humanos, para que la norma tenga sentido social hacia las nuevas genera- ciones.

La garantía de no repetición está compuesta por todas las acciones dirigidas a impedir que vuelvan a realizarse conductas con las 
cuales se afectaron los derechos de las víctimas, las cuales deben ser adecuadas a la naturaleza y magnitud de la ofensa. La garantía de no repetición está directamente relacionada con la obligación del Estado de prevenir las graves violaciones de los DDHH, la cual comprende la adopción medidas de carácter jurídico, político, administrativo y cultural que promuevan la salvaguarda de los derechos (Corte Constitucional, 2013).

Por ello, el legislador que pretenda implementar en un Estado de derecho la justicia transicional como modelo para la búsqueda de la reconciliación nacional, debe ser muy cuidadoso a la hora de establecer las pautas proce- sales que pretenden la reparación a las víctimas, so pena de no generar nuevos afectados y hechos violentos.

\section{Justicia transicional en el mundo}

Como antecedentes de esta representación de justica, tenemos el caso ale- mán que luego de terminada la segunda guerra mundial, se establecieron los juicios de Núremberg, en donde se pretendía castigar a los alemanes responsable del famoso holocausto nazi, que tuvo como víctima princi- palmente a los judíos. Dichos juicios terminaron condenando a los res- ponsables a penas de cárceles y algunos a la pena capital

Otra manifestación la encontramos en el Estado español, que una vez derrotada la dictadura del general Franco se procedió a la aplicación de esta justicia transición, en donde se renunció al enjuiciamiento de los responsables de violaciones de derechos humanos durante el régimen, por considerarlo contraproducente para la reconciliación de los españoles, por tal motivo, lo que se promovió el olvido de los hechos violentos, como alternativa definitiva para la paz.

Por su parte, Irlanda del Norte, quien también vivió su propio conflicto interno por parte del grupo extremista Irish Republican Army, más conocido como IRA, que se traduce como Ejército Republicano Irlandés, quien fue responsables de una serie de atentados en gran Bretaña, lograron un acuerdo de paz, con la firma un acuerdo en el año 1998 conocido como de Acuerdo del Viernes Santo. 


\section{La justicia transicional en Colombia}

En Colombia encontramos el caso del grupo armado revolucionario co- nocido como el Movimiento Democrático del Diecinueve de Abril- M19, quien negoció con el Estado Colombiano en un proceso de paz, la deja- ción de las armas a cambio del perdón y olvido, es decir, la impunidad de sus actos. Este grupo guerrillero, se reorganizó a la vida civil y política con la participación en la Asamblea Nacional Constituyente en el año de 1991.

Hoy por hoy, sus miembros son partícipes permanentes en la política nacional, ocupando cargos en las distintas ramas del poder público en Colombia.

Otra referencia está constituida por la ley de Justicia y Paz, Ley 975 de 2005 , la cual fue promovida con el propósito de terminar el conflicto armado con los grupos paramilitares y la subversión, esta norma se constituyó en una herramienta para el desmantelamiento de los grupos armados, fundamentados en los principios de Justicia Transicional, como la verdad, justicia y reparación.

Colombia intenta nuevamente buscar la reconciliación nacional mediante la implementación nuevamente de un sistema de justicia transicional, con la promulgación de la ley 1448 o Ley de Victimas y de restitución de tierras Por la cual se dictan medidas de atención, asistencia y reparación integrala las víctimas del conflicto armado interno y se dictan otras disposiciones.

Esta norma, además de determinar quiénes son las personas que deben considerarse como consideran víctimas del conflicto armado, establece la reparación integral de las mismas, y dentro de dicha reparación contiene una modalidad novedosa conocida como la restitución de tierras.

\section{La restitución de tierras como reparación a las víctimas y sus aspectos procesales}

La restitución de tierras es el derecho que tienen las víctimas a que se les devuelva su predio cuando éste fue despojado o abandonado a causa del conflicto armado (Ministerio de agricultura y desarrollo rural), se consti- tuye como una forma de reparación en el marco de la Ley de Victimas y Restitución de Tierras, que en dicho modelo de Justicia transicional la erige 
como una forma de que la víctima pueda recuperar o reestablecer la situación en la que se encontraba antes de que ocurriesen los hechos violatorios.

Para ello, la norma propone un proceso con condiciones especiales, que permitan garantizar el acceso de las pretensiones de la población víc- tima, entre los cuales tenemos, la creación de una jurisdicción especializada que trate exclusivamente los procesos de restitución de tierras, la creación de la Unidad de Restitución de Tierras, la inversión de la carga de la prueba, la demostración la buena fe exenta de culpa, entre otros aspectos que se observaran a continuación.

\section{La buena fe simple y la buena fe exenta de culpa en el proceso de restitución de tierras}

La buena fe es un principio elemental en el Estado de Derecho, no obstante, nuestra constitución le da un carácter supra para la protección y aplicación de derechos en su artículo 83, el cual sostiene que "las actuaciones de los particulares y de las autoridades públicas deberán ceñirse a los postulados de la buena fe, la cual se presumirá en todas las gestiones que aquellos adelanten ante ésta" (Constitución política de Colombia, art. 83).

El principio de buena fe, en lo que respecta al proceso, se concreta a que las partes no utilicen el proceso o las actuaciones de este para lograr fines fraudulentos o dolosos, o alegar hechos contrarios a la realidad o emplear medios que tiendan a entorpecer la buena marcha del procedimiento (Azula Camacho, 2006, p.81). Uno de los principios en la ley objeto de estudio, es precisamente el de la buena fe, que tiene sus cimientos en su artículo 5, en donde el Estado debe presumir la buena fe de la víctima.

Por su parte, la buena fe exenta de culpa va más allá, dado que requiere un comportamiento pulcro, libre de yerros, tal y como lo deja ver la sentencia C - 963 del 10 diciembre de 1999, M.P. Carlos Gaviria Díaz, en donde se dijo que la buena fe exenta de culpa es la necesidad "desplegar, más allá de una actuación honesta, correcta, o apoyada en la confianza, un comportamiento exento de error, diligente y oportuno, de acuerdo con la 
finalidad perseguida y con los resultados que se esperan - que están señalados en la ley". Así las cosas, en la restitución de tierras donde se exige al propietario u opositor que deberá demostrar la buena fe exenta de culpa, se le hace más gravosa su situación en el proceso.

Ahora bien, pero cuál sería la diferencia trascendental que nos trae la Justicia Transicional en la ley de Víctimas y Restitución de Tierras; ésta radica en su demostración, al respecto la Corte Constitucional señala:

Si bien es cierto que en los dos eventos se parte del supuesto de que la persona obró con lealtad, rectitud y honestidad, la buena fe simple se presume de todas las actuaciones o gestiones que los particulares realizan ante el Estado, de ahí que sea éste quien deba desvirtuarla. Por su parte, la buena fe exenta de culpa exige ser probada por quien requiere consolidar jurídicamente una situación determinada. Así, la buena fe exenta de culpa exige dos elementos: de un lado, uno subjetivo, que consiste en obrar con lealtad y, de otro lado, uno objetivo, que exige tener la seguridad en el actuar, la cual solo puede ser resultado de la realización actuaciones positivas encaminadas a consolidar dicha certeza.

Por ende, se puede afirmar como lo precisó la misma corte en dicho fallo, que la lógica que irradia el proceso es fuerte en relación con el opositor para ser flexible con las víctimas.

Este mismo artículo 5 de la Ley 1448 de 2011 antes manifestado, contempla la inversión de la carga de la prueba, en el entendido de que la víctima bastará con que presente prueba sumaria del daño sufrido, para que de manera automática sea el demandado u opositores sean los obligados, responsables o quienes detengan que soportar todo el peso de probar que los bienes inmuebles solicitados en restitución, fueron adquiridos en el marco legal, so pena de verse inmerso en conductas delictivas y tener que responder ante la justicia, dada la presunción de buena fe que la ley otorga a las víctimas, o que pierdan el derecho de percibir la compensación de que trata la norma.

\section{Inversión de la carga de la prueba}

El artículo 5 citado en su incisivo tercero, revela un punto importante para los procesos de restitución, el cual remite al artículo 78, que señala: 
ARTíCUlO 78. INVERSIÓN DE LA CARGA DE LA PRUEBA. Bastará con la prueba sumaria de la propiedad, posesión u ocupación y el reconocimiento como desplazado en el proceso judicial, o en su defecto, la prueba sumaria del despojo, para trasladar la carga de la prueba al demandado o a quienes se opongan a la pretensión de la víctima en el curso del proceso de restitución, salvo que estos también hayan sido reconocidos como desplazados o despojados del mismo predio.

Nótese, que la justicia transicional implementada para este caso, un desequilibro en el proceso, favoreciendo a la víctima quien solo deberá presentar prueba sumaria para trasladar inmediatamente la carga probatoria al demandado. Entendiendo que:

El carácter de prueba sumaria de una prueba dice relación no tanto a su poder demostrativo, sino a la circunstancia de no haber sido contradicha. Se opone, por tanto, a la controvertida, es decir, a la que ha sido practicada con citación y audiencia de la parte contra la cual se pretendehacer valer. De la cual tiene que seguirse que las pruebas sumarias son siempre extra proceso; pero que estas no tienen siempre aquel carácter, pues las hay con valor de plena prueba como ocurre con las anticipadas cuando se practican con citación de la futura parte contraria (Corte Suprema de Justicia, 2008, p. 183).

Entendemos entonces como prueba sumaria, aquella que no ha sido controvertida, lo cual denota que, para su validez plena, deberá ponerse de presente a la contraparte para que este la refute o no. Pues bien, la ley 1448 de 2011 le otorga una presunción de validez a la prueba samaria, partiendo de que se configura la buena fe de la víctima y se traslada la obligación de probar al demandado, lo cual podría constituir en desequilibrio exagerando en favor de la víctima, más aún cuando el demandado le corresponderá demostrar la buena fe exenta de culpa.

Por regla general, cada parte dentro del proceso deberá probar el supuesto de hecho con el fin de que se le otorguen pretensiones, no obstante para el caso de la restitución de tierras, la victima que solicite un predio en restitución, bastará que aporte una prueba que no ha sido controvertida 
para trasladar la carga probatoria al propietario, poseedor u ocupante actual del predio objeto de la solicitud, sin tener en cuenta el principio procesal que establece que la carga de la prueba incumbe al actor - onus probandi incumbit actori. Precisamente, el Doctor Azula Camacho en su obra deja ver que:

La carga de la prueba determina a cuál de las partes interesa demostrar los hechos que constituyen el fundamento de sus pretensiones o excepciones, según se trate de demandante o demandado, mientras que con respecto al juez constituye la manera de evitar la sentencia inhibitoria o el non liquet de que hablan los romanos. (Azula Camacho, 2015, p. 45)

Una vez presentada la demanda y aportada la prueba sumaria por parte del solicitante de restitución, se traslada la carga probatoria a quien padece la solicitud u opositor, quien de conformidad con lo dispuesto en la norma deberá probar la buena fe exenta de culpa, la cual no lo exime de la restitución del bien, sino que está dada para hacerse acreedor a una compensación.

Así las cosas, es para este caso en particular, con fundamento en la justicia transicional, en donde se otorgan bondades en favor de quien por regla general debería llevar todo el peso probatorio dentro de un proceso. Ahora bien, en el evento de que el opositor no pueda probar la buena fe exenta de culpa podría terminar siendo una víctima más en el fallo de restitución.

\section{Unidad de Restitución de Tierras y Representación de las Víctimas}

Otro aspecto importante en el proceso de restitución de tierras tiene que ver con que las víctimas pueden decidir ser representados por el Estado, para lo cual la ley en su artículo 103 ha creado la Unidad Administrativa Especial de Gestión de Restitución de Tierras Despojadas, quien a su vez tendrá la función de pagar en nombre del Estado las sumas ordenadas en las sentencias de los procesos de restitución a favor de los terceros de buena fe exenta de culpa, de conformidad con el numeral 6. Del artículo de la norma. 
Lo anterior se constituye en una abierta intervención del Estado en el proceso, dado que no solo representaría los intereses de las víctimas, sino que además sus propios intereses por razones económicas, en la búsqueda de tratar de desvirtuar la buena fe exenta de culpa para que no proceda la compensación en favor del opositor. Por ello, los opositores deben enfrentarse en el proceso de restitución, tanto a las víctimas solicitantes como al Estado que a la luz del marco normativo termina participando por sus intereses.

\section{Otros aspectos que desequilibran el Derecho de Defensa en la Restitución de Tierras}

Si bien para el siguiente caso no hay aun actuación procesal, es pertinente manifestarlo que la norma castiga a los opositores en el trámite adminis- trativo, tal y como se observa en el inciso cuarto del artículo 76 de la ley, en donde al propietario, poseedor u ocupante que le soliciten su predio en restitución, solo podrá aportar pruebas documentales para acreditar tal condición, dejando de lado los demás medios probatorios, entre otras co- sas, que por lo general la posesión, y más una la ocupación de terrenos baldíos, además de probarse documentalmente, las principales pruebas las constituyen los testimonios de testigos que conocen de la posesión u ocu- pación; lo anterior, cual se constituye en una dificultad para el poseedor u ocupante dentro del trámite.

Tal situación, la percibimos como una de las dificultades que encierra los procesos de restitución de tierras, Etapa Administrativa, es precisamente lo concerniente a la naturaleza jurídica registral del procedimiento, pues desde el punto de vista procesal limita el derecho de los terceros a ejercer una adecuada defensa. Prevé la norma que reglamenta el artículo mencionado en el párrafo anterior que la Unidad Administrativa Gestión de Restitución de Tierras Despojadas, comunicará el acto que determina el inicio del estudio de la solicitud al propietario, poseedor u ocupante predio objeto de registro, teniendo los últimos, a partir del día siguiente de la comunicación, el término de diez días, para presentar pruebas documentales que acrediten la propiedad, posesión u ocupación de buena fe sobre predio. 
Desde este instante empezamos a evidenciar los primeros tropiezos que se suscitan en la etapa administrativa de inscripción en el Registro de Tierras Despojadas y Abandonadas Forzosamente; quien actuare como tercero interviniente solo podrá aportar pruebas documentales quedando excluido los demás medios probatorios determinados por la ley, y con plena observancia tanto en actuaciones administrativas como judiciales, así mismo, siempre le ha estado vedado al tercero, conocer tanto el nombre del reclamante de restitución como los hechos que fundamentan tal solicitud, escenario que en nada facilita una intervención realmente garantista dentro del proceso, pues en el acta de recepción de información y documentación que levanta la Unidad de Restitución de Tierras, el tercero solo se favorece de lo que su buena memoria e intuición puedan ofrecerle o pueda recordar, por lo tanto, se estaría ejerciendo una defensa a ciegas, dado que se desconocen unos supuestos facticos determinantes para la adopción de una decisión de tipo administrativa previa a la procesal.

Si dentro de un trámite administrativo o un proceso judicial, limitamos la presentación de cualquier medio probatorio, estaríamos coartando la posibilidad de defenderse con los recursos que se tengan en el momento, así pues, si la norma solo me permite presentar pruebas documentales, para probar la calidad de propietario, poseedor u ocupante, estaríamos trasgrediendo el articulo 29 superior, dado que el derecho a defenderse es fundamental para cualesquiera de las partes tanto en los tramites o procesos, más aun si se trata de calidades que podrían ser probadas por otros medios de prueba, cual es la de posesor o de quien explota un bien baldío.

\section{Igualdad Procesal en el Proceso de Restitución}

Todo proceso debe tener un equilibrio entre las partes que permitan la participación de todos en igualdad de condiciones, en ese sentido, la Corte Constitucional mediante sentencia C-690 de 2008, consagra este principio de la siguiente forma:

Principio fundamental del derecho procesal es el de la igual- dad de las partes en el proceso, lo que significa que quienes a él concurren de manera voluntaria o por haber sido citados en forma oficiosa, deben tener las mismas oportunidades procesales para la realización plena de sus garantías a la bilateralidad de la 
audiencia. En desarrollo de ese postulado esencial al debido proceso, se tiene que (i) a la presentación de la demanda corresponde la oportunidad de darle contestación dentro del término legal y previo traslado de la misma; (ii) a la oportunidad de pedir pruebas de cargo, corresponde la de pedir pruebas de descargo por la parte demandada; (iii) a la oportunidad de alegar por una de las partes, le corresponde también la misma a la otra parte, del mismo modo que sucede con el derecho a la impugnación de las providencias proferidas por el juzgador en el curso del proceso, de tal manera que siempre exista para la parte a la cual le es desfavorable lo resuelto la oportunidad de impugnar la decisión respectiva. (Corte Constitucional, C-690 de 2008)

Los anteriores requisitos se entienden esenciales dentro del proceso para pregonar la igualdad procesal. No obstante, cuando nos encontramos frente a una justicia transicional en donde existen valores trascendentales y relevantes como la paz y la reconciliación nacional, es pertinente otorgar ciertos privilegios dentro del proceso a quienes están en condiciones desiguales, en este caso las víctimas, con cargo a la contraparte, es decir, los opositores.

Por su parte, el artículo 88 de la Ley 1448 de 2011, contempla las oposiciones dentro del proceso, y señala:

Artículo 88. Oposiciones. Las oposiciones se deberán presen- tar ante el juez dentro de los quince (15) días siguientes a la solicitud. Las oposiciones a la solicitud efectuadas por particulares se presentarán bajo la gravedad del juramento y se admitirán, si son pertinentes. Las oposiciones que presente la Unidad Administrativa Especial de Gestión de Restitución de Tierras Despojadas, cuando la solicitud no haya sido tramitada con su intervención deberá ser valorada y tenida en cuenta por el Juez o Magistrado.

La Unidad Administrativa Especial de Gestión de Restitución de Tierras Despojadas, cuando no haya actuado como solicitante podrá presentar oposición a la solicitud de restitución. 
Al escrito de oposición se acompañarán los documentos que se quieran hacer valer como prueba de la calidad de despojado del respectivo predio, de la buena fe exenta de culpa, del justo título del derecho y las demás pruebas que pretenda hacer valer el opositor en el proceso, referentes al valor del derecho, o la tacha de la calidad de despojado de la persona o grupo en cuyo favor se presentó la solicitud de restitución o formalización. El texto subrayado fue declarado EXEQUIBLE por la Corte Constitucional mediante Sentencia C-330 de 2016).

Obsérvese que, en el primer inciso, generaliza a todas las oposiciones que presenten, sin redundar, los opositores, sin tener en cuenta que estos pue- den ser de tres tipos, como lo expuso la Corte Constitucional en Sentencia C-330 de 2016:

92. Los artículos demandados hacen referencia a personas que actúan en el trámite de restitución de tierras como "opositores", es decir, quienes presentan “oposición” dentro del trámite. De acuerdo con el artículo 88 de la Ley de víctimas y restitución de tierras existen tres tipos de oposiciones distintas: (i) aquellas que persiguen demostrar la calidad de víctima de despojo en relación con el mismo predio objeto del trámite de restitución de tierras (supuesto regulado por el artículo 78 de la misma Ley); (ii) las destinadas a tachar la condición de víctima del solicitante y (iii) las que pretenden demostrar la existencia de una relación jurídica o material sobre el predio objeto del trámite, generada por una conducta de buena fe exenta de culpa. La expresión demandada en los artículos 88, 91, 98 y 105 de la Ley de víctimas y restitución de tierras tiene que ver exclusivamente con el tercer tipo de oposición.

Por ello, el Alto Tribunal en dicha sentencia, donde estudió la constitucio- nal de la expresión exenta de culpa, del inciso tercero del artículo 88 antes citado, falló declarando exequible condicionalmente argumentando que: 
La norma demandada generaría una discriminación indirecta, en la medida en que exige a todos los opositores interesado demostrar una conducta calificada y no da un trato diferencial a personas que lo merecen, es decir, los segundos ocupantes en condición de vulnerabilidad que no tuvieron relación directa ni indirecta con el despojo o el abandono forzado de los predios

En ese orden de ideas, la Corte Constitucional, alivia un poco la actuación procesal de los segundos ocupantes como opositores en el proceso de restitución de tierras, en la búsqueda de equilibrar las cargas del proceso sin que se vean vulnerado el derecho de igualdad procesal.

\section{Efectos del desequilibrio en el proceso de restitución de tierras Primero la justicia, luego la paz}

Para tratar este punto, debemos ahondar en el fin mismo de las leyes y por supuesto del derecho, tanto sustancial como procesal, precisamente por- que la Restitución de Tierras tiene como fin la reparación de las víctimas mediante la devolución de la tierra de las cuales fueron despojadas o aban- donadas a causa del conflicto armado. Esta meta tiene un marco norma- tivo, que se basa en principios sustanciales y procesales, entre ellos la jus- ticia transicional, como lo estipula el artículo 8 de la Ley 1448 de 2011 en donde pretende que se satisfagan los derechos a la justicia, la verdad y la reparación integral a las víctimas, se lleven a cabo las reformas institucio- nales necesarias para la no repetición de los hechos y la desarticulación de las estructuras armadas ilegales, con el fin último de lograr la reconciliación nacional y la paz duradera y sostenible.

Si el fin de la norma es lograr la reconciliación nacional y la paz duradera y sostenible, debe existir un equilibrio entre lo pretendido y las herramientas procesales sentadas para lograr ese derecho sustancial, es decir, que los mecanismos procesales deben ser proporcionados y justos para las partes intervinientes en el proceso, sin que se exagere hacia una de ellas, porque la finalidad que tiene el proceso es la búsqueda de la justicia para alcanzar la convivencia social o la paz.

El Doctor Javier Barreca Mairal (2005), platea el modo de llegar a la paz, señalando que: 
La Justicia se relaciona con la paz, al constituir el camino o la vía fundamental, para la realización de esta última en la convivencia social. Sin justicia, no es posible la paz ("pax est opus justitiae"). En una sociedad en la impera la injusticia, la paz no es real, sino pura apariencia; en el fondo, una auténtica guerra, bien soterrada o declarada de manera abierta. Cuando reina la injusticia, la sociedad vive en conflicto, en lucha, en guerra, sea esta guerra manifiesta o no. Puede darse el caso de que la guerra no se haya desatado de modo expreso y visible para todos, por diversas razones, pero que alcance cotas muy altas de crueldad. Así como solo en la medida en que una sociedad participa en el valor de la justicia progresa el grado de su profundización en la paz. Por eso se dice, en definitiva, que la paz es la obra de la justicia. La justicia que trae la paz debe, por otra parte, ser interpretada como equidad, que procede, en último extremo, de la benevolencia, en cuanto a caridad o generosidad general (p. 133).

Vemos entonces que, en la medida de que los principios procesales de la ley de Victimas y Restitución de Tierras no generen el equilibro justo para las partes, esta, no podrá lograr sus objetivos, entre otros, el de reparar a las víctimas mediante la devolución de los predios, los cuales hoy se encuentran en cabeza de otros titulares a quienes también se les debe brindar garantías en el proceso. Sin embargo, lo que existe son un conjunto de prerrogativas que desproporcionan el proceso en favor de una de las partes, obligando a la otra a soportar cargas que podría considerarlas injustas. Luego entonces, la norma en lugar de lograr la reconciliación nacional, podría constituirse en un nuevo foco de violencia, logrando un efecto contrario al que obedece su creación.

Según investigaciones realizadas por organismos del orden nacional e internacional, la ley ha traído una serie de amenazas, intimidaciones y hasta asesinatos de líderes solicitantes de restitución de tierras. Es decir, una norma que presume la reconciliación nacional y que provoca actos violentos, yerra en sus principios y para nada se constituye en un ordenamiento jurídico justo, por consiguiente no alcanzara el fin del derecho y su sen- 
tencia es el fracaso, más aun, cuando el proceso establecido no es lo suficientemente equilibrado, así como por ejemplo, el solo hecho de que se invierta la carga de la prueba y el opositor o demandado deba demostrar la buena fe exenta de culpa para aspirar a una compensación, podría presumir a ese opositor como un victimario, dado que este es quien corre con el peso de demostrar su legitimidad como propietario, poseedor u ocupante de los predios solicitados en restitución, lo que no es nada sano en el fin de la norma.

Teniendo en cuenta que la finalidad de un proceso es que, de:

Carácter general, remoto o mediato, se contraen a un interés de índole común, que atañe a toda la comunidad o conglomerado social, y consiste en la preservación de la armonía y la paz entre los integrantes del grupo, lo cual se logra evitando la justicia por propia mano o de manera directa. Como acertadamente lo dice Guasp (Citado por Azula Camacho, 2015, p. 40), el fin normal del proceso es "el mantenimiento de la paz justa o de la justicia pacífica". O, de acuerdo con Carnelutti (Citado por Azula Camacho, 2015, p. 40)," "paz con justicia podría ser, de ese modo, el lema del derecho procesal. Ni paz sin justicia, ni justicia sin paz" (Azula Camacho, 2015, p. 40).

Deberá ser los más justo posible, sin que las consecuencias del mismo provoquen la utilización de las vías de hecho por parte de los actores en el mismo.

\section{Investigaciones sobre víctimas que solicitan restitución}

La Human Rights Watch, publicó una investigación el 17 de septiembre de 2013, en donde precisa la violencia y amenazas contra deslazados que reclaman restitución de tierras, lo anterior, se reflejado en asesinatos que incluyen líderes, reclamantes individuales, familiares de estos y sus abogados. Por otra parte, precisa el informe que,

En una carta enviada en marzo de 2013 al Presidente Santos, decenas de jueces especializados en causas de restitución de tierras 
de todo el país pidieron que se les concedieran medidas de protección y manifestaron que temían seriamente por su seguridad en los siguientes términos: "Son de público conocimiento los atentados a que se han enfrentado las víctimas reclamantes, sus líderes y los miembros de las organizaciones que los respaldan. Los servidores de la justicia estamos igual o mayormente expuestos [a los ataques], en consideración a que somos precisamente quienes ordenamos la restitución jurídica y material de los bienes despojados". Como fue señalado por el director del programa gubernamental de protección, la estrategia de los agresores es "matar pocos para enviar un mensaje a muchos (Human Rights Watch, 2013).

Es el mismo Estado, quien a través de la rama que imparte justicia, solicita tal protección dado que son ellos los encargados de dictar las sentencias que concederán o no la restitución de las tierras a los solicitantes y si se conceden o no las respectivas compensaciones y se sienten en iguales con- diciones de amenaza que los solicitantes de restitución, más aún cuando la ley desequilibra el proceso que ellos mismos deben llevar. Señala además la investigación:

Por ejemplo, Ermes Vidal Osorio y Ever Cordero Oviedo, dos importantes líderes de la población desplazada de Valencia, Córdoba, fueron asesinados con una diferencia de 20 días en marzo y abril de 2013, presuntamente a manos de los Urabeños. Ambos pertenecían a un comité que se conformó en Valencia para asegurar que las víctimas participaran en la implementación de la Ley de Víctimas. Poco después del homicidio de Cordero, las amenazas y los actos de intimidación por parte de supuestos miembros de los Urabeños consiguieron que 34 de sus familiares abandonaran Valencia, incluidos 22 niños. (Negrita y subrayado fuera del texto) (Human Rights Watch, 2013)

Se revela también, la cifra de personas que reclaman la restitución de tie- rras mediante la Ley de Victimas (Ley 1448 de 2011) y que denunciaron amenazas, cifra que llegó a 447 personas en todo el país, siendo Antioquia 
el Departamento con más amenazados con un total de 65 personas. Es decir, en solo año y medio de aplicación de la ley, ya se constituía como una fuente de violencia en el país

En otro artículo publicado por la revista semana el 4 de agosto de 2017, un lustro después de entrada en vigencia la ley 1448 de 2011, revela un lento avance de los procesos de restitución, teniendo en cuenta que la norma lleva la mitad de su vigencia, precisando el estudio que de las 87.118 solicitudes presentadas ante los estrados, sólo una minoría, apenas 2.943, han sido resueltas judicialmente en favor de las víctimas. Un mínimoporcentaje comparado con las miles presentadas hasta ahora, sostiene la Fundación Forjando Futuros (SEMANA, 2016). En este orden de ideas, la reparación de las víctimas por la vía de la restitución de tierras, representaría un costo muy alto en amenaza, atentados y homicidios frente a los procesos resueltos jurídicamente en favor de las víctimas.

Otro estudio más reciente, publicado en el reporte semestral ¿Dónde y cómo están matando a los líderes rurales? emitido por el Observatorio de Restitución y Regulación de Derechos de Propiedad Agraria (2017) y recientemente publicado, el asesinato de líderes rurales no ha disminuido, el fenómeno no va a desaparecer solo y se necesitan políticas públicas para combatirlo.

El cuadro que se presenta a continuación, muestra el número de líderes asesinados por cada año, iniciando desde 2005 y hasta el 2016, en nuestro estudio tomamos como referencia desde mediados del año 2011, fecha en que entró en vigencia la Ley de Víctimas y Restitución de Tierras.

\section{Gráfica 1}

\section{Líderes asesinados por año de ocurrencia}

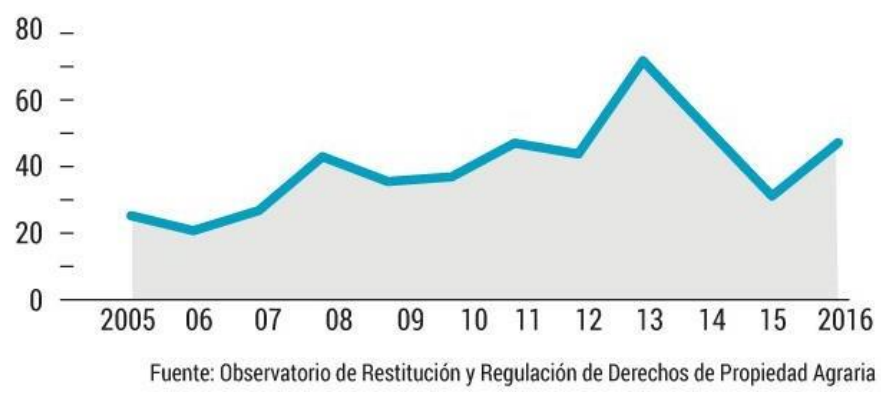


Nótese claramente en la gráfica, que una vez inicia la aplicación de la ley de Victimas y restitución de tierras, incrementa de manera sustancial el asesinato de líderes reclamantes de tierras entre el 2012 y 2013, llegando inclusive a su punto más crítico.

Es bastante claro que la norma con la que se pretende reparar a las víctimas de despojos y abandono forzado a causa del conflicto armado y cuya finalidad es la reconciliación nacional a través de una paz duradera, presenta fallas estructurales en materia sustancial y procesal, y que por el contrario a la reconciliación, se ha convertido en una fuente generadora de violencia. En primer lugar, sobre las víctimas reclamantes de restitu- ción, quien son amenazados y asesinados, y en segundo lugar, a los propietarios, poseedores u ocupantes actuales de los bienes inmuebles solicitados en restitución quienes a raíz de las cargas procesales que les atañe soportar, lo hacen ver victimario.

\section{Conclusiones}

Conforme a lo anteriormente expuesto en cada aparte de este escrito, nuestro semillero ha llegado a las siguientes conclusiones:

1. El modelo de justicia transicional se estable en los países donde se presentan violaciones a los derechos humanos con el fin de resolver los conflictos, buscar la reconciliación nacional y buscar una paz estable y duradera.

2. La ley de restitución de tierras, bajo el modelo de justicia transicional pretende devolver las tierras a las víctimas que han sido despojadas o hayan abandonado sus predios forzosamente por causa del conflicto armado.

3. En el proceso de restitución de tierras se traslada la carga de la prueba a los opositores de la misma, asumiendo la buena fe de la víctima que aporte prueba sumaria del daño sufrido.

4. La ley 1448 de 2011 contiene una serie de privilegios dentro del proceso de restitución de tierras que desequilibran el proceso en favor de la víctima y con cargo a los opositores. 
5. Para la Corte Constitucional, la exigencia de la buena fe exenta de culpa a los segundos ocupantes en su calidad de opositores, constituye en una discriminación indirecta por exigirles una conducta calificada.

6. La ley de Víctimas y restitución de tierras se ha convertido en una fuente de amenazas, atentados y asesinatos de líderes y reclamante de tierras.

\section{Referencias}

Azula Macho, Jaime. Manual de Derecho Procesal. Tomo I. Teoría General del

Proceso. Novena Edición. Editorial Temis. 2006. p. 81.

Azula Camacho, Jaime. Manual de Derecho Procesal. Pruebas judiciales. Edi- torial Temis. 2015. P. 40 y 45

Barraca Mairal, Javier. Pensar el Derecho. Curso de Filosofía Jurídica. Edi- ciones Palabra S.A. 2005. P. 133

Bernal Acebdeo, Gloria Y Alvarez Borras, Nhora. Aprendizaje Significativo de la Ley de Justicia y Paz: GTZ. 2009. p. 60

Carnelutti, Francesco. Como se hace un proceso. Santa Fe de Bogota. Edit. Temis, 1997, Pág. 25

Centro Internacional Para La Justicia Transicional,

Enfoque. Justicia transicional. Recuperado de https://www.ictj.org/sites/default/files/ICTJ-Global-Transitional-Justice-2009-Spanish.pdf

Guasp, Jaime. Derecho Procesal Civil. T. I, $3^{\text {a }}$. Ed., Madrid, Instituto de Estudios Políticos, 1968, pág. 25

Human Rights Wath. El Riesgo de Volver a Casa. Septiembre 17 de 2013. Véase: https://www.hrw.org/es/report/2013/09/17/el-riesgo- devolver-casa/violencia-y-amenazas-contra-desplazados-que-reclaman

Observatorio de Restitución y Regulación de Derechos de Propiedad Agraria. (2017, Mayo). Catalogo en Línea. Recuperado de http://www.observatoriodetierras.org/donde-y- como-estan-matandoa-los-lideres-rurales-variables-municipales-en-el- asesinato-de-lideressociales-rurales/

Osorio, Marcela. Periódico El espectador. Radiografía del Asesinato de Lideres Rurales. Véase: http://www.elespectador.com/noticias/politica/radiografia-del-asesinato-de-lideres-rurales-articulo-696669 
Parra Quijano, Jairo. Manual de Derecho Probatorio. Librería Ediciones del Profesional Ltda. 2008. P. 183

República de Colombia. Constitución Política de 1991.

Artículo 83. Primera Edición. Imprenta nacional

República De Colombia. Congreso De La Republica. Ley 1448. (10, Junio, 2011).

Por la cual se dictan medidas de atención, asistencia y reparación integral

a las víctimas del conflicto armado interno y se dictan otras disposiciones.

Diario Oficial. Bogotá D.C., 2011. No. 48096

República de Colombia. Presidencia de la República. Decreto 440 de Marzo 11 de 2016. Primera Edición. Imprenta Nacional

República de Colombia. Corte Constitucional. Sala Plena. Sentencia del 28 de Agosto de 2013. M.P. Jorge Ignacio Pretelt Chaljub. Expe- diente D9499

República de Colombia. Corte Constitucional. Sala Plena.

Sentencia C-963 de 10 de Diciembre de 1999. M.P. Carlos Gaviria Díaz. Expediente D-2450.

República de Colombia. Corte Constitucional. Sala Plena.

Sentencia C-330 de 23 de Junio de 2016. M.P. María Victoria Calle Correa. Expediente D-11106

República De Colombia. Corte Suprema De Justicia. Pronunciada dentro del proceso ordinario de Luis Hernando y Hugo Al- berto Guarnizo contra los herederos de Napoleón Escalante. Mag. Pon. Dr. Humberto Murcia Ballén. República de Colombia. Corte Constitucional. Sala Plena. Sentencia C-690 del 9 de Julio de 2008. M.P. Nilson Pinilla Pinilla. Expediente D- 6939

República de Colombia. Corte Constitucional. Sala Plena. Sentencia C-690 del 9 de Julio de 2008. M.P. Nilson Pinilla Pinilla. Expediente D- 6939

República de Colombia. Ministerio de Agricultura y Desarrollo Ru- ral. Atención al ciudadano. https://www.minagricultura.gov.co/aten- cionciudadano/preguntas-frecuentes/Paginas/Restitucion-de-Tie- rras.aspx 
Revista Semana. Las pobres cifras de la restitución de tierras. Publicado el día 04/08/2016. Véase: http://www.semana.com/nacion/articulo/restitucion-de-tierras-forjando-futuros-entrega-informe-sobrereparacion/468495

Torré, Abelardo. "Norma, Derecho y Filosofía". En revista La Ley. T XLIII, 1946. Citado por: MONROY CABRA, Marco Gerardo. Introducción al Derecho. Temis. 2010. P. 156

Uprimny Yepes, Rodrigo, Otros. ¿Justicia Transicional Sin Transición? Ver- dad, Justicia y Reparación para Colombia. Ediciones Antropos. 2006. P. 52 